\title{
Eu Aceito - Eu Ofereço: Insights para desenvolvimento de um artefato digital para inovação social através da economia colaborativa
}

I Accept - I Offer: Insights for the development of a digital artifact for social innovation through the collaborative economy

Manoella Guennes Tavares de Oliveira; Mestranda; UFPE; m.guennes@gmail.com

Ney Dantas; PhD; UFPE; ney.dantas@gmail.com

Leonardo Castillo; PhD; UFPE; leonardo.a.gomez@gmail.com

\section{Resumo}

Este artigo se propõe a discutir o Design enquanto fator primordial no desenvolvimento de artefatos digitais em prol da inovação social através da economia colaborativa. Sua construção se deu durante a vivência da disciplina Tópicos em Artefatos Digitais do curso de pós-graduação em Design da Universidade Federal de Pernambuco. Além do contexto teórico no qual é inserida, abrange também a prática da pesquisa com a identificação de aprimoramentos que os modelos atuais necessitam e com a construção de uma proposta preliminar das bases projetuais de um artefato digital que visa conectar mulheres ofertantes e aceitantes de produtos e serviços para uso e pós-uso em rede compartilhada.

Palavras Chave: Inovação Social; Economia Colaborativa; Artefatos Digitais.

\begin{abstract}
This article aims to discuss design as a primary factor in the development of digital artifacts in favor of social innovation through the collaborative economy. Its construction took place during the experience of the discipline <omitido para revisão cega> of the <omitido para revisão cega> course in Design of the <omitido para revisão cega>. In addition to the theoretical context in which it is inserted, it also encompasses the research practice identification of improvements that current models need and the construction of a preliminary proposal of the design bases of an application that aims to connect women offering and accepting products and services for use and post-use on a shared network.
\end{abstract}

Keywords: Social Innovation; Collaborative Economy; Digital Artefacts. 


\section{Introdução}

Em um período de oscilações conjunturais (econômicas, ambientais, sociais, financeiras, tecnológicas), onde todos os modelos tem sido repensados de forma a reestruturar todos os padrões em que se insere a sociedade, a economia colaborativa encontra suas bases práticas nos conceitos de maximização do uso e exploração de um bem ou recurso, em prol de aumentar os benefícios deles recorrentes, tendo em vista a diminuição do período ocioso deste mesmo bem ou recurso. Esse fenômeno tem sido viabilizado devido à disseminação do uso de dispositivos eletrônicos que possibilitam a conexão e interação de pessoas em redes de compartilhamento, bem como pela disponibilização de métodos de avaliação de experiência e qualidade percebida pelos usuários de bens ou serviços.

O principal foco da economia colaborativa é o compartilhamento peer-to-peer, ou seja, de pessoa para pessoa, ainda que nesse processo, hajam empresas envolvidas na interface entre as pessoas. É importante salientar que estas não executam qualquer intervenção direta na relação entre "oferta" e "demanda".

No teor prático do contexto da inovação social, sendo esta a consequência de modelos como o da economia colaborativa - podendo ser também a causa, se houver a intenção de projetar novos funcionamento sociais, proposto aqui como atividade do design e do seu profissional, o designer -, é salutar olhar para os grupos locais - que tem como base alguns critérios como o que Manzini (2017) define como SLOC (small, local, open e conectted), entender o seu funcionamento na prática e identificar oportunidades no que diz respeito a aprimorá-los tendo por base a teoria construída. Visto que a prática da inovação é atrelada à melhoria contínua, a relevância deste estudo dá-se na necessidade de observação de realidades, especialmente de grupos e comunidades que se formam, estando estes interligados a conceitos que vão moldar a sociedade do futuro, e sendo o designer um grande agente transformador do que será planejado, desenvolvido, executado e, finalmente moldado para as pessoas e suas relações entre si e entre o meio em que se encontram.

Este artigo tem como problemática a compreensão das formas que a teoria acerca de conceitos de "Inovação Social" e "Economia Colaborativa" podem aprimorar a prática de funcionamento em grupos já existentes no modelo "Eu aceito - Eu ofereço" em prol de gerar ideias preliminares para o desenvolvimento de um artefato digital. Como objetivo geral, tem-se gerar insights que sirvam de bases preliminares para uma proposta de um artefato digital de economia colaborativa em nível nacional para mulheres como artefato digital de inovação social. Como objetivos específicos, são enumerados:

a. Estudar os conceitos pertinentes ao assunto;

b. Fazer um levantamento de informações pertinentes aos grupos - na rede social Facebook - de economia colaborativa no modelo "Eu aceito - Eu ofereço" existentes no Brasil, enfatizando os feitos por e para mulheres;

c. Pesquisar as práticas e experiências das usuárias desses grupos, bem como fatores percebidos que precisam ser aprimorados;

d. Identificar pontos importantes para a criação de um artefato digital que visa aperfeiçoar o funcionamento dos grupos estudados, de forma a gerar inovação para o impacto social através da prática da economia colaborativa. 
Para que os objetivos deste estudo fossem alcançados com sucesso, a perspectiva metodológica utilizada tem abordagem indutiva - no qual pressupõe-se apesar do grupo estudado, os dados particulares serão entendidos como comuns para grupos maiores -, de caráter quantitativo e qualitativo, visto que é das respostas abertas e da possibilidade de expressar-se que os insights e ideias tem maior possibilidade de serem gerados.

Em termos de procedimento, optou-se pelo método estruturalista, pois este melhor se adequa aos objetivos propostos, desde que "caminha do concreto para o abstrato e vice-versa, dispondo, na segunda etapa, de um modelo para analisar a realidade concreta dos diversos fenômenos" (MARCONI e LAKATOS, 2003, p. 111).

As técnicas utilizadas para fundamentar o estudo e atuar no sentido da busca pelos resultados foi a pesquisa bibliográfica e a aplicação de questionário digital online, sendo esta ferramenta aberta e fechada, respondidos por 296 pessoas que participam de grupos no modelo "Eu aceito - Eu ofereço" em todo o território nacional disponíveis na rede social Facebook, no período de 01 de setembro de 2017 a 31 de outubro de 2017.

\section{Inovação Social}

A inovação é um termo que, na atualidade, tem sido utilizado em um amplo espectro de conceituações e aplicações. Pinheiro e Alt (2011, p. 24) definem inovação como "fruto da criatividade colocada em prática com o intuito de gerar resultados positivos para o negócio e criar impacto positivo para as pessoas". Nesse sentido, a inovação relaciona-se com a geração de soluções que modificam o modo como as pessoas vivem e trabalham, equilibrando benefícios para os negócios e para a sociedade de modo geral.

Anteriormente compreendida apenas por aspectos de superioridade tecnológica e excelência em desempenho, visão essa insuficiente do ponto de vista do desenvolvimento global (VIANNA et al., 2012), a inovação passou a ser vista como objetivo de transformação de valores em prol da sociedade e suas relações, gerando diferencial para todos os envolvidos no processo.

O termo inovação social, desse modo, é descrito por Mulgan (2007) como novas ideias que funcionam na satisfação de objetivos sociais, ou ainda, atividades inovadoras incentivadas pelo objetivo de guiar a solução de necessidades sociais e que são predominantemente desenvolvidas e difundidas através de organizações cujos propósitos primários são sociais. Goldenberg (2004) complementa definindo-a como o desenvolvimento e aplicação de atividades novas ou melhoradas, iniciativas, serviços, processos ou produtos concebidos para lidar com os desafios sociais e econômicos enfrentados por indivíduos e comunidades. Novy e Leboult (2005) fazem uma abordagem como sendo ela derivada da satisfação de necessidades humanas básicas, do aumento de participação política de grupos marginalizados, crescimento na capacidade sociopolítica e do acesso a recursos necessários para reforçar direitos que levem à satisfação das necessidades humanas e à participação.

Quando colocados os conceitos de inovação e inovação social lado-a-lado, pressupõe-se que toda inovação deveria pensar primeiramente na sua efetividade enquanto fator social, visto que a vida das pessoas, de modo coletivo - não apenas como usuários isolados e individuais -, deveria ser tomada como prioridade. Desse modo, ao afirmar que estas são inovações que são sociais em seus fins e em seus meios, Hubert (2010) tem a mais adequada definição a que se propõe este estudo, ao defini-la, ainda, como novas ideias (produtos, serviços e modelos) que 
atendam simultaneamente as necessidades sociais (de forma mais eficaz do que as alternativas) e cria novas relações sociais ou colaborações. São inovações que não são apenas boas para a sociedade, mas também melhoram a sua capacidade de ação. Ou seja, é relevante considerar todas as consequências advindas do artefato inovador em âmbito social, todas as possibilidades implementadas que aumentam a capacidade da sociedade de agir, conforme complementam Murray et al. (2010).

Sendo aferida essa abordagem acerca do design social, pode-se sugerir que a sua prática também tem consequências no que diz respeito à sustentabilidade, ou seja, à manutenção ambiental, econômica e social. Para Manzini (2017), algumas características são inerentes à inovação social como o único caminho a ser trilhado em prol da prática de se pensar e agir de modo sustentável em meio à crise da conjuntura (social-econômica-ambiental). Esse cenário emergente - chamado pelo autor de "Cenário SLOC"1" -, é baseado na intersecção de três principais campos: a revolução verde (e os sistemas ambientalmente amigáveis), a propagação das redes (e as organizações distribuídas, abertas e pessoa-para-pessoa que são geradas) e, finalmente, a difusão da criatividade (e as respostas aos problemas cotidianos que são concebidos e implementados por uma variedade de atores sociais). Como pode-se notar, todos as áreas mencionadas por Manzini (2017) partem de um ponto que se dissipa em diversas consequências, sendo todas as que foram descritas consideradas causas a novas relações sociais, seja do homem com a sociedade ou com o meio.

\section{Design}

O design, por ser definido como a atividade de pensar e executar soluções criativas e efetivas para problemas específicos e reais, e ter como objetivo "estabelecer as qualidades multifacetadas de objetos, processos, serviços e seus sistemas em ciclos de vida completos", é fator primordial como meio de criar, desenvolver e executar projetos de inovação social, sendo, portanto, considerado "o fator central da humanização inovadora de tecnologias e o fator crucial do intercâmbio cultural e econômico" (MOZOTA, 2011, p. 16).

Acerca desse aspecto, Araújo (2014, p. 28) versa que "nos últimos anos, o design tem sido um forte aliado no desenvolvimento de inovações, capaz de criar rupturas no atual modelo econômico devido às suas características, ganhando destaque ao englobar aspectos estratégicos de produtos e serviços". Pelo fato de envolver questões que partem para a criação e desenvolvimento de ideias, projetos ou planos na criação e desenvolvimento de soluções práticas, é tamanha a importância de considerá-lo como ferramenta para trazer inovação à sociedade como um todo (Löbach, 2001).

Neumeier (2010, p. 17), questiona que se a inovação impulsiona à diferenciação, o que, então, impulsiona à inovação? A resposta, escondida à primeira vista, é o design. O design contém os conhecimentos para assinalar futuros possíveis, criar produtos emocionantes,

\footnotetext{
${ }^{1}$ Cenário SLOC é uma alusão a small, local, open e connected - pequeno, local, aberto e conectado, em tradução livre -, quatro adjetivos que sintetizam o sistema sociotécnico em o cenário descrito é baseado: um sistema de produção e consumo distribuído no qual o "global" é uma rede de sistemas locais conectados, com controle e participação dos indivíduos e da comunidade.
} 
construir pontes para consumidores acabarem com grandes problemas, entre outras ações. Segundo o autor, "the fact is, if you wanna innovate, you gotta design"."

A busca pela inovação tem identificado no design e nos procedimentos que desenvolvem as criações humanas, ferramentas criativas, fortes e efetivas (ALVARENGA et al., 2014). Bezerra (2011, p. 21) compara o ato de inovar ao ato de plantar, no qual as inovações seriam frutos de um processo - "o processo de criação, de design". Dessa forma, o design é entendido como o motor da inovação, sendo o profissional de design responsável pela inserção dos valores que ele deseja transformar na sociedade. Ainda nesse contexto, de acordo com Margolin e Margolin (2004), o modelo social do design tem como intuito não apenas satisfazer as necessidades humanas, mas, principalmente, contribuir para as transformações sociais de um modo mais abrangente - diferentemente dos modelos de projetos desenvolvidos frequentemente no campo do design, que foca na indústria e no mercado.

\section{Economia Colaborativa}

O capitalismo industrial e o hiper-consumismo, modelos econômicos que foram desenvolvidos até o século XX (BOTSMAN, 2017), pelas contas de Rifkin (2012), em sua obra The Zero Marginal Cost Society: The internet of things, the collaborative commons and the eclipse of capitalism - que menciona que no novo modelo econômico, seguido por grandes e inovadoras empresas, o custo marginal de produção do primeiro para o segundo bem tende a zero, enfatizando o crescimento escalável da oferta de produtos e serviços, bem como o processo de desintermediação e oferta direta, o que também elimina os custos marginais para ao consumidor -, continuará dominante apenas pelos próximos 50 anos. Como disrupção no que tange aos modelos emergentes, o autor afirma que na segunda metade deste século a economia colaborativa será prevalecente.

Esse modelo socioeconômico é baseado em um ecossistema ${ }^{3}$ sustentado pelo compartilhamento de produtos, serviços e recursos (tanto materiais quanto humanos) de pessoapara-pessoa (peer-to-peer), priorizando as necessidades coletivas ao invés dos interesses individuais, de forma que reconhecer a relevância das relações mais humanas e do comprometimento com a construção do processo é o que impulsiona a sua execução. Racon (2017) enumera algumas práticas características da economia colaborativa: o uso compartilhado de salas comerciais, a troca ou empréstimo de equipamentos, caronas solidárias, permuta na prestação de serviços e várias outras iniciativas tornaram-se mais que alternativas para diminuir gastos e inspiraram o surgimento de novas empresas.

Conforme compara Chase (2015), nos anos 2000, a maior rede de hotéis do mundo possuía 645 mil quartos em mais de 100 países, em uma rede que demorou mais de 65 anos para se consolidar. O Airbnb (plataforma que conecta pessoas que querem alugar quartos com outras que tem quartos disponíveis), após 6 anos de lançamento, já disponibilizava mais de 700 mil quartos através de seus colaboradores. Além do Airbnb, outras plataformas são inseridas no contexto da economia colaborativa, tendo em vista que o produto ou serviço ofertado é

\footnotetext{
2 "O fato é que se você quer inovar, tem que projetar", em tradução livre.

3 Para Hawley (2017), ecossistema abrange a estrutura de relações dentro da comunidade e entre a comunidade e o meio em que ela se encontra.
} 
relacionado a recursos ociosos e subutilizados, e o modelo de negócio diz respeito ao investimento, principalmente, na plataforma - ou seja no artefato digital, definido como "qualquer produto com informatização embutida" (SANTOS, 2009) -, e os bens oferecidos para a prestação dos serviços são fornecidos por parceiros (a exemplo da pessoa que tem o quarto disponível em sua casa, na plataforma Airbnb). São outros exemplos de economia compartilhada: sistemas de compartilhamentos de bicicletas (Bike Itaú), prestação de serviços profissionais locais e troca de tempo (Getninjas, Bliive), compartilhamento de conhecimento (Skillshare), venda de roupas e acessórios usados (Enjoei), vendas de qualquer produto novo ou usado (OLX), modos alternativos de hospedagem (Couchsurfing, Airbnb, Windu), serviços de transporte aluguel e compartilhamento de carros (Blablacar, Uber, Zipcar, Fleety, Toyota Rent a Car) e sistema de troca de livros (BookMooch). De acordo com Mendonça (2017), a economia colaborativa deve chegar a movimentar 335 bilhões de dólares mundialmente em 2025, conforme projeção da consultoria PricewaterhouseCoopers.

As relações de troca e compartilhamento são intrínsecas ao funcionamento de comunidades. Na natureza, a organização das abelhas e das formigas são exemplos de como esses processos acontecem de forma orgânica e natural. Na sociedade, não diferentemente, estão presentes desde os primórdios. Entretanto, o que tem viabilizado esse processo de mudanças de paradigmas socioeconômicos em prol desse modelo compartilhado é a propulsão e a disseminação de uma rede que conecta virtualmente várias pessoas ao mesmo tempo, ou seja, a internet (SOUZA, 2013). Acerca desse tema, Souza (2016, p. 6) afirma que "os holofotes lançados sobre o tema não decorrem de a economia compartilhada ser uma inovação, mas pela multiplicação de iniciativas nessa seara na última década, potencializadas pela disseminação de dispositivos eletrônicos portáteis".

Assim como a existência dessa particularidade do impulsionamento da economia colaborativa devido aos avanços tecnológicos e digitais, a moeda de troca nesse modelo, fundamental para as operações ocorram, é a avaliação de experiências que, conforme versa Bostman (2017), é baseada na confiança. A autora afirma que a "reputação será a moeda que diz que você pode confiar em mim", e que "de fato, a reputação é uma moeda que eu acredito que se tornará mais poderosa do que o nosso histórico de crédito no século XXI". De acordo com Rasmussen (2017), "como mediadoras das negociações colaborativas, empresas como o Fleety, o Tem Açúcar, o DogHero, o Uber, o Airbnb, entre várias outras, desenvolvem seus próprios mecanismos de confiabilidade, seja na forma da verificação de um documento ou de uma entrevista".

A possibilidade de acesso, ou acessibilidade, a todas as pessoas a tecnologias inseridas na economia colaborativa é uma das características que a insere no contexto da inovação social (MANZINI, 2017). E dentro desse cenário, as empresas que atuam como intermediárias criam soluções acessíveis para os consumidores que estão em situação financeira menos favorável, inclusive tendo suas funções destacadas em períodos de crise econômica no mundo, visto que estes serviços "oferecem fluxo de renda exclusivos para pessoas que precisam de dinheiro extra ou horários de trabalho flexíveis" (CROWDTASK, 2017). Ainda, além de flexibilizar as relações de oferta e demanda de produtos e serviços, Sundararajan (2016), em sua obra The sharing economy: The end of employment and the rise of crowd-based capitalism, propõe também que a economia compartilhada representará o crescimento do microempreendedorismo e a geração de 
trabalhadores "auto-empregados" que são empoderados a trabalhar nos locais, períodos e intensidades que desejarem.

Levando em consideração os reflexos da economia compartilhada - igualmente conceituada à economia colaborativa neste estudo -, Souza (2017) acrescenta outros benefícios de ordem social, ambiental e econômica, sendo eles: economia de recursos naturais, diminuição da poluição ambiental, aumento das possibilidades de empreendedorismo pessoal, maior diversificação em qualidade e preço de produtos e serviços oferecidos aos consumidores, aumento da possibilidade de renda extra nas horas vagas dos trabalhadores convencionais, diminuição na desigualdade da renda, aumento de intercâmbio cultural e menores custos de transação.

\section{5 "Eu aceito - Eu ofereço"}

O primeiro grupo no modelo "Eu aceito - Eu ofereço" existente na internet surgiu no ano de 2016, na cidade de Vitória da Conquista, quando uma mulher queria pedir ajuda para concluir uma atividade, mas não sabia a quem pedir. Inicialmente fez a solicitação na rede social Facebook, e logo obteve sucesso (GNT, 2017). Tentando fazer outros testes com esse mesmo modelo, ela criou uma "comunidade feminina nascida e criada no ambiente virtual que propõe ações práticas e reais de ação mútua", agindo como intermediária nos processos de ofertar e aceitar qualquer que seja o produto ou serviço, seja ele novo ou já usado, de forma gratuita e em rede. É importante ressaltar que não são relações de troca, a usuária não precisa aceitar para oferecer, ou vice-versa.

Desse primeiro grupo, que abrangia apenas a região baiana próxima à cidade, outros grupos foram se formando, sendo priorizado o atendimento regional para que houvesse a possibilidade de o processo ser executado. Dessa forma, várias comunidades locais foram desenvolvidas, onde o maior ativo é a relação que surge no contexto da operação. Hoje são mais de 37 grupos e páginas dessa rede social (e que já tem se difundido para outras, como o WhatsApp), que promovem aspectos relacionados aos modelos da economia colaborativa - ou compartilhada -, mesmo que involuntariamente. Além do tradicional modelo restrito apenas para mulheres cis e trans, conforme a fundadora do grupo menciona em entrevista ao canal GNT (2017) - que hoje já contam com mais de 25 mil usuárias no total -, outros grupos mistos (homens e mulheres) também foram criados.

Para fins de alcançar os objetivos desta pesquisa, foi priorizado o público feminino, pois, durante a pesquisa e a geração de ideias, identificou-se que as mulheres tem $96 \%$ maior aderência às relações que a economia colaborativa envolve, além de que sentem-se mais "seguras quando sei que somos todas mulheres", conforme mencionou uma das mulheres que faz parte de um dos grupos e que respondeu ao questionário.

Os grupos funcionam da seguinte forma: uma pessoa compartilha que está oferecendo ou aceitando algum bem ou serviço (o qual ela esteja precisando obter ou doar) e aguarda os comentários dos outros usuários que, ao visualizarem a comunicação e tiverem interesse, respondem e combinam independentemente as condições de demanda e oferta, como a forma, data e local de entrega. Todas as operações que fazem parte do processo acontecem de forma gratuita. Roupas que não são mais utilizadas, animais para adoção, livros que estão ociosos, informações sobre diversos assuntos, até uma "ajudinha para deixar o filho porque precisa trabalhar" são recorrentes em todos os grupos que fizeram parte desse estudo. Ainda, algumas 
mulheres utilizam como estratégia de marketing ao "oferecer sessões grátis" de algum serviço, estimulando o empoderamento e o empreendedorismo feminino.

Ao total, 296 pessoas que fazem parte de algum ou alguns dos grupos responderam ao questionário, que visou pesquisar a prática e a experiência das usuárias a fim de gerar insights para a construção das bases preliminares para a proposta do artefato digital. Dentre as informações relevantes que foram coletadas:

- Mais de $98 \%$ das mulheres tem acima de 18 anos;

- $89 \%$ reside na região Nordeste, especialmente nos estados de Pernambuco e Bahia - embora tenha usuárias que residem em estados sulistas como São Paulo e Santa Catarina;

- Mais de $57 \%$ é solteira;

- Mais de $60 \%$ possui renda de até $\mathrm{R} \$ 1500$;

- Mais de $95 \%$ possui smartphone;

- Mais de 93\% acessa a internet através do smartphone;

- $66 \%$ costuma fazer compras online;

- $67 \%$ fazem parte de grupo "Eu aceito - Eu ofereço" apenas para mulheres;

- $71 \%$ já ofereceu ou aceitou algum produto ou serviço no grupo;

- Mais de $69 \%$ das operações foi feita para alguém da mesma cidade;

- Mais de $80 \%$ das operações foram bem-sucedidas;

- Mais de $52 \%$ costuma oferecer, e quase $48 \%$ costuma aceitar;

- Mais de $63 \%$ costuma oferecer ou aceitar produtos (em detrimento de serviços);

- Os itens que mais fazem parte da operação são "livros", "roupas" e "informações";

- Os valores mais importantes mencionados como motivadores para a permanência e utilização dos grupos foram "Empatia" (62,7\%), "Sororidade" (54\%), "Empoderamento Feminino" (52,9\%), "Confiança" (46,4\%), "Gratuidade" (43,5\%), "Economia Circular" (42,8\%) e "Sustentabilidade" (39,5\%);

- $\quad 78,8 \%$ acredita ser positiva a existência de um grupo (ou outras plataformas) "Eu aceito - Eu ofereço" em nível nacional.

Além dos dados quantitativos adquiridos por meio da pesquisa, algumas informações relevantes foram mencionadas. "Acho que o mais importante nesses grupos é a sustentabilidade. A possibilidade de dar um significado ou uma utilidade ao que não te serve mais. A possibilidade de receber um produto sem ter que pagar por isso. O meio ambiente agradece.", disse uma das usuárias que reside em Itabuna - BA, cidade que abrange mais de $40 \%$ de todo o público que participou da pesquisa. Uma outra entrevistada, que reside em Feira de Santana - BA, disse que julga "importante a solidariedade desses grupos, que não oferecem vendas de produtos e serviços, mas apoio por vezes emocional e financeiro". Nesse contexto, é importante identificar o quanto os aspectos afetivos dos grupos tem sido relevantes na construção dessas comunidades, sendo elas locais, e sempre com a presença de um moderador. 


\section{Conclusão}

Os assuntos abordados nesse estudo foram de extrema relevância do que diz respeito ao design como motor para a prática da inovação social, sendo a economia colaborativa um aspecto que tem sido, e continuará sendo, o modelo socioeconômico vigente em um futuro bem próximo.

Tendo como objetivo central a geração de ideias para a construção de um artefato digital a partir do contato mais próximo com as supostas usuárias, em resumo, tem-se os seguintes pontos referentes ao processo, ilustrados na Figura 1:

- Segurança: Por ser fator primordial, é importante o cadastro de dados pessoais como CPF, RG, Telefone, E-mail, Comprovante de Residência e Antecedentes Criminais;

- Flexibilidade: Por meio de conversa independente das usuárias "aceitante" e "ofertante", elas ficam responsáveis por combinar aspectos de entrega do bem ou serviço, de forma que a relação e "peer-to-peer";

- Credibilidade: A avaliação de experiência é de extrema importância, visto que é a moeda de troca que as usuárias podem utilizar nesse sistema de economia compartilhada onde as transações são gratuitas.

Figura 1 - Insights gerados para o processo de criação de funcionalidades do artefato digital

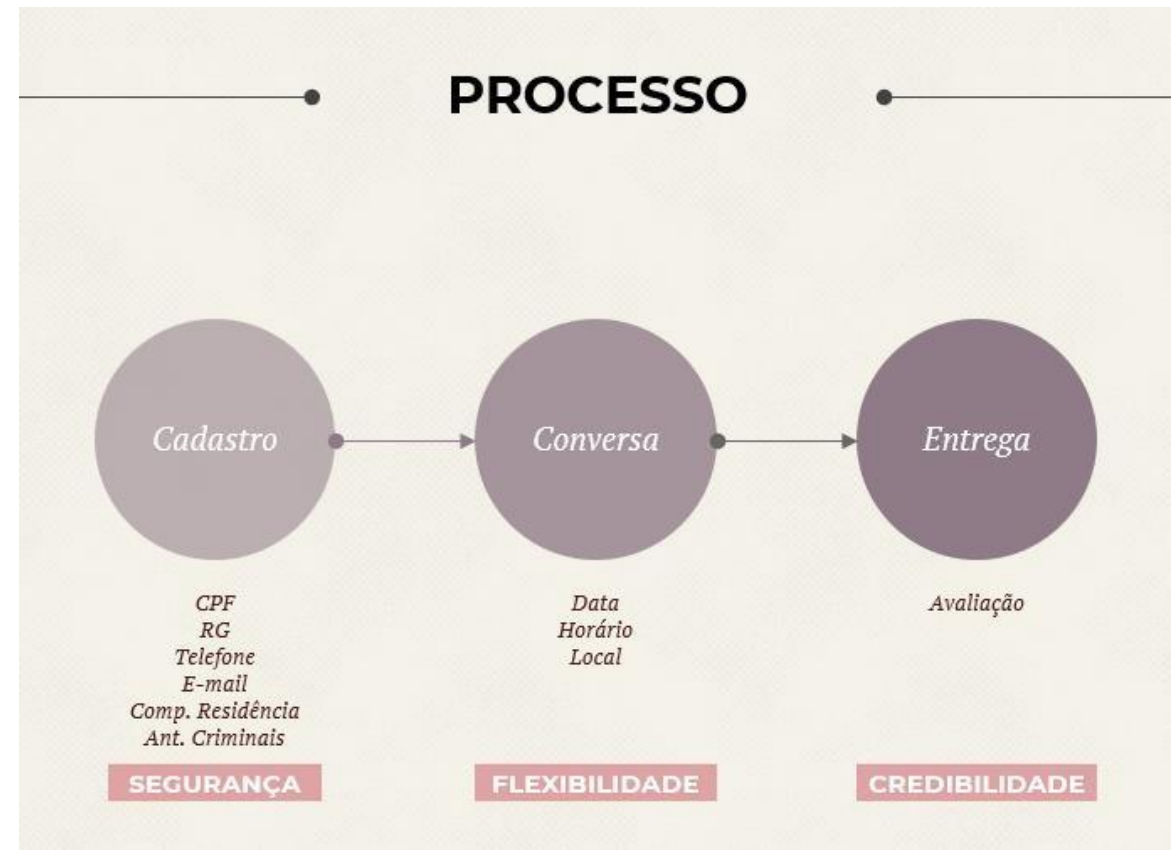

Fonte: o autor

Ainda, outros insights foram gerados, no que diz respeito ao âmbito geral, conforme

Figura 2.

- Quanto menor a distância geográfica das usuárias, menor será a distância afetiva: Grupos com mediações e encontros regionais podem ser utilizados como estratégia de relacionamento;

- Mulheres confiam mais em mulheres: a maioria demonstrou maior tendência a participar ativamente na ocasião de haver apenas mulheres; 
- Relações de desapego x relações de necessidade: As relações mais importantes geradas não são de transação de bens ou serviços, mas de afeto, amizade, empatia, sororidade e apoio;

- Empoderamento e empreendedorismo feminino: Formas de incentivar as mulheres empreendedoras são fatores essenciais para esse modelo de negócio.

Figura 2 - Visão geral das realidades sociais modificadas a partir do artefato digital

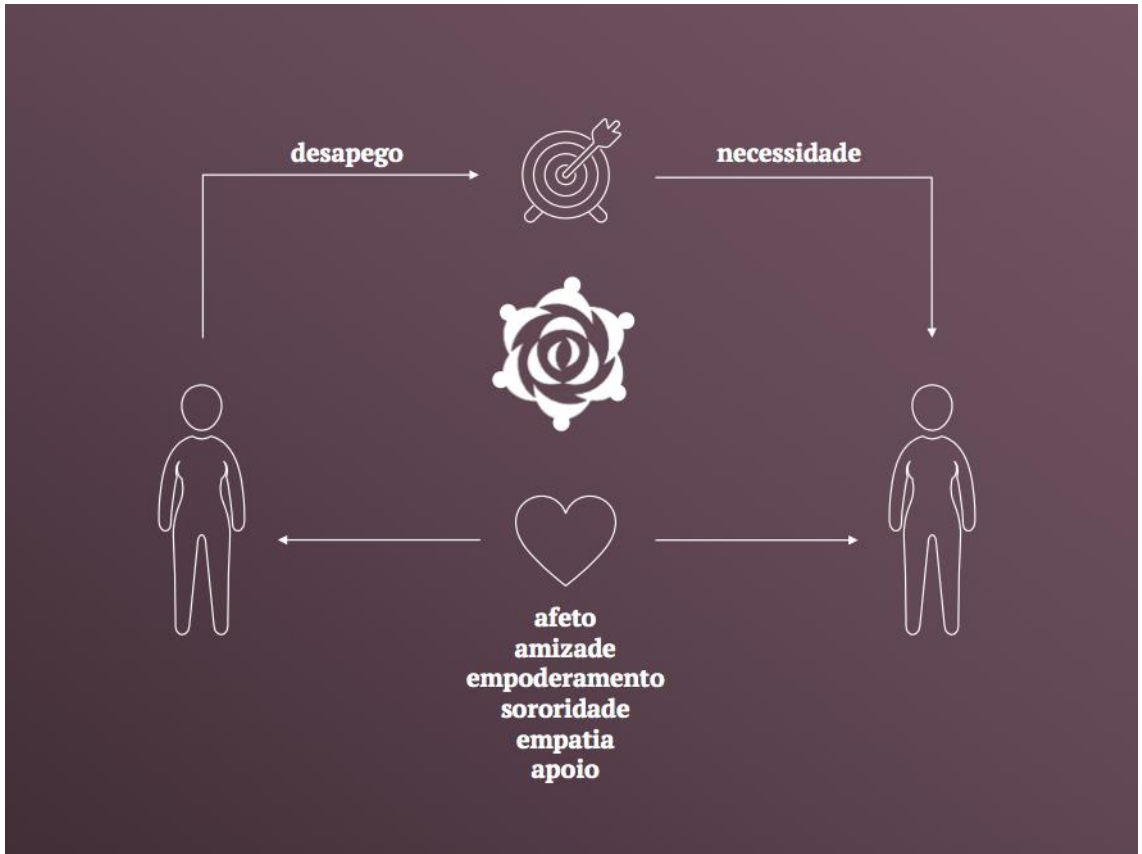

Fonte: o autor

Dessa forma, todos os objetivos a que se propunha este estudo foram concluídos com sucesso, visto que trata-se de um estudo preliminar, o qual abre diversas outras possibilidades. Dentre elas, a mais inovadora de todas: a criação e o desenvolvimento de um artefato digital, que descobriu-se indicado ser um aplicativo - visto os dados relativos ao acesso da internet ser via smartphone -, de economia colaborativa para mulheres à nível nacional em prol da inovação social.

\section{Referências}

AlvarengA, T. H. P.; SANTOS, B. S.; PIEKARSKI, C. M.; MATOS, H. A. S. A.; FRANCISCO, A. C. Conceitos, definições e características da inovação no setor têxtil brasileiro. Revista de Design, Inovação e Gestão Estratégica. Rio de Janeiro, v.5, n.ำ 5, mai 2014.

ARAÚJO, A. B. Design Thinking como ferramenta de inovação sociocultural. Estudo de caso: Casa da Cultura. 2014. 109f. Monografia (Graduação em Design) - Curso de Graduação em Design, Universidade Federal de Pernambuco. Caruaru, 2014.

BOSTMAN, R. The case for collaborative consumption. In: TED Talks, 2017. (https://www.ted.com/talks/rachel_botsman_the_case_for_collaborative_consumption/transcri pt\#t-974257)

GOLDENBERG, M. Social innovation in Canada: How the non-profit sector serves Canadians... and it can serve them better. In: Urban Centre, 2017. (http://www.urbancentre.utoronto.ca/pdfs/elibrary/CPRN_Non-Profit-Sector-in- C.pdf) 
GNT. Eu aceito, eu ofereço: Grupo virtual que permite pedir ajuda ou ajudar alguém sem esperar nada em troca. In: GNT, 2017. (http://gnt.globo.com/programas/saia- justa/videos/5541008.htm)

HAWLEY, A. H. Human ecology: Persistence and change. In: Muni, 2017. (https://is.muni.cz/el/1431/jaro2008/Z4044/um/GMreader3_1_Hawley.pdf)

LÖBACH, B. Design industrial: base para a configuração dos produtos industriais. Trad. Freddy Van Camp. São Paulo: Editora Blucher, 2001.

MARCONI, M. A.; LAKATOS, E. M. Fundamentos de metodologia científica. 5 ed. São Paulo: Atlas, 2003.

MANZINI, E. Small, local, open, connected: Design for social innovation and sustainability. In: Parsons, 2017. (http://sds.parsons.edu/designdialogues/?post_type=article\&p=501)

MENDONÇA, H. Compartilhar, a moda que veio para ficar. In: El País, 2017. (https://brasil.elpais.com/brasil/2017/01/09/economia/1483984486_528116.html)

MOZOTA, B. B.; KLÖPSCH, C.; COSTA, F. C. X.. Gestão do design: usando o design para construir valor de marca e inovação corporativa. Trad. Lene Belon Ribeiro. Porto Alegre: Bookman, 2011.

MULGAN, G. Social innovation: What it is, wy it matters, and how it can be accelerated. In: The Young Foundation, 2007. (http://youngfoundation.org.com)

MURRAY, R. CAULIER-GRICE, J. MULGAN, G. The open book of social innovation. In: NESTA/The Young $\quad$ Foundation, 2010. (www.nesta.org.uk/publications/assets/features/the_open_book_of_social_innovation.)

NEUMEIER, M. The designful company. In: LOCKWOOD, T. (org.). Design thinking: integration innovation customer experience, and brand value. 3 ed. Nova lorque: Alworth Press, 2010.

PINHEIRO, T.; ALT, L. Design Thinking Brasil: empatia, colaboração e experimentação para pessoas, negócios e sociedade. Rio de Janeiro: Elsevier, 2011.

RASMUSSEN, B. Economia colaborativa: Ela quer te ajudar a economizar, faturar e restaurar a sua fé na humanidade. In: Hypeness, 2017. (http://www.hypeness.com.br/2015/05/economiacolaborativa-como-o-senso-de-comunidade/)

SANTOS, D. L. F. Design de artefatos digitais baseados em padrões e plataformas. In: Repositório UFPE,

2017.

(http://repositorio.ufpe.br/bitstream/handle/123456789/3194/arquivo2196_1.pdf?se quence $=1 \&$ isAllowed $=\mathrm{y}$ )

SOUZA, I. G. Economia Colaborativa. In: Câmara Legislativa, 2017. (http://www2.camara.leg.br/acamara/documentos-e-pesquisa/estudos-e-notas-tecnicas/areas-daconle/tema10/2016_13983_economia-colaborativa_iuri-gregorio-de-souza)

SUNDARARAJAN, A. The sharing economy: The end of employment and the rise of crowd-based capitalism. Cambridge: The MIT Press, 2016.

VIANNA, M.; VIANNA, Y.; ADLER, I. K.; LUCENA, B.; RUSSO, B. Design Thinking: Inovação em negócios. Rio de Janeiro: MJV Press, 2012. 